\title{
O professor de Física na escola pública estadual brasileira: desigualdades reveladas pelo Censo escolar de 2018
}

The Physics teacher in the Brazilian state public school: inequalities revealed by the 2018 School Census

\author{
Matheus Monteiro Nascimento*10 \\ ${ }^{1}$ Universidade Federal do Rio Grande do Sul, Instituto de Física, Porto Alegre, RS, Brasil.
}

Recebido em 8 de maio de 2020. Revisado em 21 de maio de 2020. Aceito em 23 de maio de 2020

\begin{abstract}
Este texto aborda o tema da distribuição de professores de Física em atuação nas escolas públicas estaduais brasileiras. Os microdados do Censo escolar de 2018 foram utilizados como fonte de dados. Metodologicamente estatísticas descritivas e de análise multivariada de dados foram realizadas. Os resultados indicam que apenas 20 por cento dos professores de Física das escolas públicas estaduais do país possuem formação específica. As desiguais distribuições revelam que as regiões Centro-Oeste e Norte são as mais impactadas. A falta de oportunidades de acesso e permanência nos cursos de licenciatura influenciam especialmente mulheres e indígenas. Os resultados apresentados neste texto podem contribuir para o delineamento de ações e políticas no âmbito da formação docente.
\end{abstract}

Palavras-chave: Professores de Física, desigualdades, Censo escolar, formação de professores.

This text presents results about the distribution of physics teachers working in Brazilian state public schools. The research used the 2018 school census microdata as data source. Methodologically, this study is based on descriptive statistics and multivariate data analysis. The results indicate that only 20 percent of physics teachers in state public schools have specific training. The uneven distribution reveals that the Midwest and North regions are the most impactful. The lack of opportunities for access and permanence in undergraduate courses especially influences women and indigenous people. The results presented in this study can contribute to the design of actions and policies within the scope of teacher training.

Keywords: Physics Teacher, Inequalities, School Census, Teacher training.

\section{Introdução}

A formação de professores é uma linha de pesquisa reconhecidamente sólida na área do Ensino de Física. Uma discussão sempre presente nesta linha temática é a preocupação com a falta de docentes de Física nas escolas públicas brasileiras. Para os autores que previamente estabeleceram este diálogo, a evidência da falta de professores [1] e as recomendações de se aumentar e qualificar a formação docente [2], levaram a um crescimento no número de cursos de licenciatura em Física no país [3], resultado de um forte investimento público na expansão da educação superior desde o início dos anos 2000 [4]. O aumento no número de vagas no ensino superior, contudo, não garante a solução do problema [5], [6]. Questões como a baixa atratividade da carreira e a evasão dos cursos são elementos que complexificam ainda mais o cenário da falta de professores.

Por isso, com base neste contexto questiona-se: qual é o atual efetivo de professores de Física em atuação na escola pública estadual brasileira? Deste número, quantos possuem formação específica na área? Qual a distribuição de docentes de Física por região, por sexo e por cor/et-

*Endereço de correspondência: matheus.monteiro@ufrgs.br nia? Estudar o perfil dos docentes se justifica na medida em que apresenta informações sobre uma realidade que muitas vezes escapa da percepção dos agentes públicos $[7]$.

\section{Seleção da Amostra}

A pesquisa realizada teve como fonte os microdados do Censo da Educação Básica disponibilizados pelo INEP todos os anos na sua página da internet 1 . Todo o processo de seleção da amostra e de análise estatística foi realizado com o suporte do ambiente de programação $\mathrm{R}$ [8]. Para se chegar na amostra de docentes que lecionam Física no Brasil nas escolas públicas estaduais brasileiras, foi necessário a realização de alguns filtros. Com os dados do Censo de 2018 abertos no R, foram primeiramente selecionadas as pessoas que exercem função na escola como Docente. As outras opções possíveis e descartadas foram Auxiliar/Assistente Educacional, Profissional/Monitor de atividade complementar, Tradutor Intérprete de Libras, Docente Titular - coordenador de tutoria (de módulo ou disciplina) - EAD ou Docente Tutor - Auxiliar

Encontrado em http://portal.inep.gov.br/web/guest/ microdados. 
(de módulo ou disciplina) - EAD. Em seguida, foram selecionados os docentes que exercem mediação pedagógica presencial, em detrimento das atividades semipresenciais ou a distância, com etapas de escolarização consecutivas (regular).

Como o foco desta pesquisa é a escola pública estadual brasileira, foram selecionados apenas aqueles que lecionam em instituições desta dependência administrativa. Por fim, foram filtrados os dados selecionando apenas os docentes que afirmam lecionar a disciplina de Física. Isto não exclui aqueles que lecionam outras disciplinas além da Física, nem garante que estes docentes tenham a formação específica na área. Com isso, após todo o processo de seleção dos dados, resultou-se uma amostra de 44706 professores que lecionam Física nas escolas públicas estaduais do Brasil. Este número corresponde a aproximadamente 2 por cento dos mais de 2 milhões de professores em atividade no país. Por região, observa-se que 16412 docentes que lecionam Física estão localizados no Sudeste, 13846 no Nordeste, 6185 no Sul, 4904 no Norte e 3359 no Centro-Oeste.

\section{Resultados e Discussões}

Dos 44 mil docentes que lecionam Física nas escolas públicas estaduais do país, quantos são de fato licenciados em Física? Analisando os resultados nota-se que apenas 9 mil professores que lecionam Física possuem licenciatura na área, o que corresponde a apenas 20 por cento do total. Quando analisadas as regiões isoladamente, percebe-se que o Centro-Oeste possui apenas 15 por cento de professores de Física com formação específica na área; Norte 18 por cento; região Nordeste 19 por cento; Sudeste 21 e Sul 28 por cento. O baixo índice de licenciados em Física nas escolas públicas estaduais do Brasil é um elemento chave para análises da situação da escola brasileira, afinal, a adequação da formação docente é um fator altamente correlacionado com a qualidade da educação [9]. Enquanto a meta 16 do Plano Nacional da Educaçãd ${ }^{2}$ procura garantir a formação de 50 por cento dos professores da educação básica em nível de pós-graduação, a realidade social indica a necessidade de um olhar mais atento para a formação inicial docente.

Focando apenas naqueles que possuem formação específica na área, outra variável demográfica importante de ser analisada é a distribuição dos docentes em relação ao sexo. O Censo escolar permite apenas uma escolha binária: feminino ou masculino. Ao todo no Brasil tem-se 2990 docentes do sexo feminino com formação específica e 6089 docentes do sexo masculino com a mesma formação. Percebe-se, com isso, que apenas um terço dos professores das escolas públicas estaduais lecionando Física com licenciatura na área são do sexo feminino. Esta proporção é muito próxima dos 27 por cento de mulheres

2 Encontrado em http://pne.mec.gov.br/18-planossubnacionais-de-educacao/543-plano-nacional-de-educacaolei-n-13-005-2014 filiadas na Sociedade Brasileira de Física [10], indicando que as desigualdades em relação ao gênero na área de pesquisa Física também se revelam nas licenciaturas da área. Chama a atenção que esta desigualdade é ainda maior em algumas regiões do país. O número de professores do sexo masculino é quase quatro vezes maior do que do sexo feminino na região Nordeste. Por outro lado, observa-se uma igualdade muito interessante na região Sul do Brasil, sugerindo que os estados pertencentes a esta região vêm realizando ações que se revertem num maior número de mulheres formadas em cursos de licenciatura em Física.

Sobre a distribuição da cor da pele/etnia, os resultados obtidos mostram uma distribuição semelhante àquela indicada pelo último Censo populacional realizado no Brasil em 2010. Uma profissão que possui distribuição, em termos de cor/etnia, semelhante à da população em geral, como os resultados revelam que é o caso da Física, poderia sugerir a existência de uma igualdade no processo de escolha e seleção de profissões no país. Contudo, sabe-se que a situação é distinta. Os cursos mais concorridos são aqueles de maior prestígio simbólico e maior remuneração econômica, influenciando significativamente no perfil dos ingressantes [11].

Após a descrição detalhada das distribuições dos professores de Física em relação à formação específica na licenciatura em Física, em relação ao sexo e a cor da pele/etnia, foi realizada uma Análise de Correspondência Múltipla a fim de se obter uma representação da interconexão destas variáveis, juntamente com as regiões do Brasil. Esta técnica é muito utilizada na análise multivariada de dados para se observar a associação entre variáveis categóricas [12], semelhantes às que fazem parte desta pesquisa. O sociólogo Pierre Bourdieu foi pioneiro em utilizar Análises de Correspondência para estudar a configuração do espaço social francês [13], seja no que diz respeito às classes sociais [14] ou aos cientistas e instituições científicas [15]. Neste tipo de análise, a distância entre as categorias das variáveis, representadas em um mapa bidimensional, indicam o grau de associação entre elas, ou seja, quanto mais próximas duas categorias estiverem no mapa, maior a sua associação [12]. Por este caráter relacional, as Análises de Correspondência são muito utilizadas para expressar configurações de espaços sociais [12], [13], inclusive no próprio ensino de Física [16]. No caso do presente trabalho, esta ferramenta fornecerá uma visualização da distribuição dos professores de Física, a partir das suas características, no território nacional. A Figura 1 mostra o resultado da Análise de Correspondência.

Como referência para analisar o mapa obtido, foca-se na separação entre professores de Física com formação específica (Com Form.) e sem formação na área (Sem Form.). Nota-se que estas categorias aparecem em posições totalmente opostas no mapa, como de fato deveria ser. O seu posicionamento próximo da origem da dimensão horizontal facilita a visualização, de forma que quanto mais para cima estiverem as categorias mais próximas 


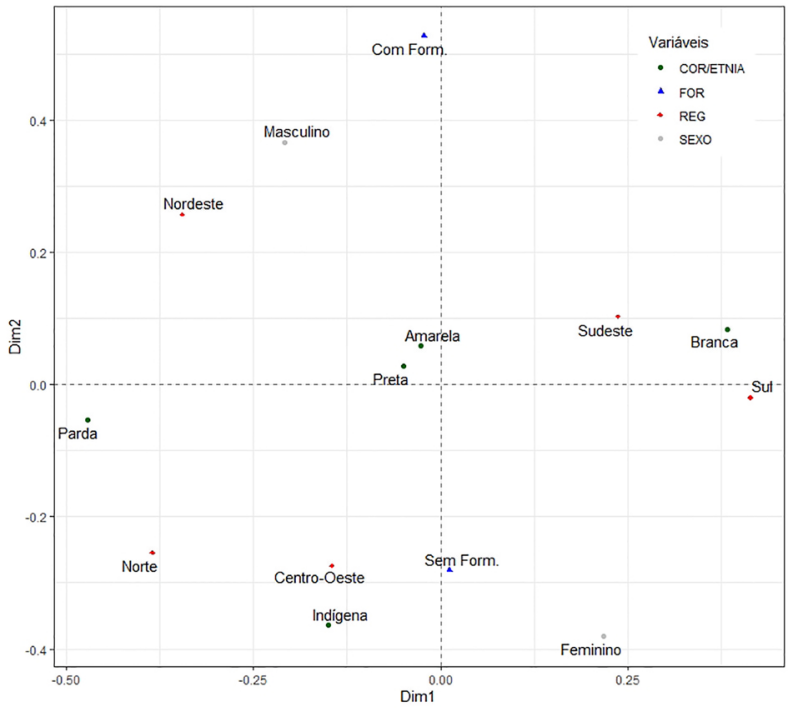

Figura 1: Configuração nacional dos professores de Física que atuam na rede pública estadual. Fonte: Autor. Dados: Censo da Educação Básica de 2018.

dos docentes com formação; e quanto mais para baixo mais próximas dos professores sem formação.

Em relação ao sexo, percebe-se que professores homens estão muito mais associados com formação específica do que as mulheres. Este resultado reforça o que vem sendo indicado pela literatura da área [10]. Sobre as regiões do país, fica claro que as regiões Centro-Oeste e Norte são as que sofrem mais com a falta de professores de Física com formação específica, como já indicado anteriormente. Destaca-se a região Nordeste, que relacionalmente às outras regiões aparece mais associada aos professores de Física com formação específica. Isto somente acontece pois esta é a região com a maior proporção de professores do sexo masculino em relação ao sexo feminino do país, aproximando assim as duas categorias no mapa. A cor da pele aparentemente não se diferencia pela formação dos professores, com exceção dos professores indígenas, revelando mais uma dimensão das desigualdades brasileiras.

Em resumo, a Análise de Correspondência nos permite identificar que existe uma desigual distribuição de professores de Física com formação nas escolas públicas estaduais brasileiras. As categorias mais impactadas pelas desigualdades associadas aos contextos formativos refere-se ao sexo feminino, aos indígenas e as regiões centro-oeste e norte. Dessa forma, este resultado pode contribuir para discussões sobre políticas públicas de formação de professores de Física no contexto brasileiro.

\section{Considerações Finais}

Neste trabalho objetivou-se realizar um estudo quantitativo a partir dos microdados do Censo escolar de 2018 a fim de visualizar a atual situação dos professores de
Física do país. A pesquisa se concentrou nos docentes que atuam nas escolas públicas estaduais brasileiras. A amostra de dados foi constituída por 44706 professores que lecionam Física nas escolas públicas estaduais do Brasil. Os resultados indicaram desigualdades, subjacentes a formação docente, ainda latentes na área. Em média, apenas 20 por cento dos professores de Física em atuação nas escolas públicas brasileiras são licenciados em Física. Mostrou-se que as regiões norte e centro-oeste são as mais impactadas, sendo que nesta última apenas 15 por cento dos professores de Física possuem formação específica. Em relação a outras variáveis relevantes, indicamos que as mulheres e os indígenas são grupos mais atingidos pela má distribuição de formação de professores de Física no país.

Este estudo pode ser utilizado como instrumento para a elaboração de ações, a nível nacional, de promoção da formação docente. Em vez de simplesmente abrir vagas ou cursos, é preciso organizar estas políticas de forma que elas contribuam preferencialmente para os grupos e regiões específicos. Por fim, indica-se que um estudo futuro sobre a distribuição dos cursos de licenciatura em Física do país se faz necessário para identificar se as regiões mais necessitadas estão sendo de fato contempladas. Ademais, uma investigação aprofundada sobre a região sul poderia indicar quais ações de estímulo ao ingresso e a permanência de mulheres na Física fazem com que esta região tenha um número praticamente igual de homens e mulheres formados e lecionando Física.

\section{Referências}

[1] J.A. Peres Angotti, Rev. Bras. Ensino Fis. 28, 143 (2006).

[2] O. Borges, Rev. Bras. Ensino Fis. 28, 135 (2006).

[3] S.T. Gobara e J.R.B. Garcia, Rev. Bras. Ensino Fis. 29, 519 (2007).

[4] M.S. de Camargo, Atos Pesqui. em Educ. 1, 176 (2015).

[5] R.S. Araujo e D.M. Vianna, Ciência Educ. 17, 807 (2011).

[6] J. Uibson, R.S. Araujo e D.M. Vianna, em XXI Simpósio Nac. Ensino Física (Uberlândia, 2015).

[7] G. Hirata, J.B.A. Oliveira e T.M. Mereb, Ens. Avaliação e Políticas Públicas em Educ. 27, 179 (2019).

[8] $\mathrm{R}$ Core Team, $R$ language definition ( $\mathrm{R}$ Foundation for Statistical Computing, Vienna, 2000).

[9] M.M. Nascimento, C. Cavalcanti e F. Ostermann, Rev. bras. Estud. Pedagog. 101, 118 (2020).

[10] D.P. Menezes, Cad. Bras. Ensino Física 34, 341 (2017).

[11] M.M. Nascimento, O acesso ao ensino superior público brasileiro: um estudo quantitativo a partir dos microdados do Exame Nacional do Ensino Médio. Tese de Doutorado, Universidade Federal do Rio Grande do Sul, Porto Alegre (2019).

[12] M. Greenacre, Correspondence analysis in practice (Chapman and Hall/CRC, New York, 2017).

[13] J. Blasius, F. Lebaron, B. Le Roux e A. Schmitz, Empirical Investigations of Social Space (Springer, Cham, 2019). 
[14] P. Bourdieu, La distinción: criterio y bases sociales del gusto (Taurus, Madrid, 2016).

[15] P. Bourdieu, Homo academicus (Stanford University Press, Stanford, 1988).

[16] M.M. Nascimento, E. Antunes Júnior, C. Cavalcanti e F. Ostermann, Rev. Bras. Pesqui. em Educ. em Ciências 19, 775 (2019). 